\title{
Novel Endotracheal Tube Cuffs: Improving the Seal as a Barrier to Leakage
}

Nosocomial infections are a challenge to the base credo of doing no harm to our patients. Ventilator-associated pneumonia (VAP) is an iatrogenic complication in patients who require invasive mechanical ventilation. Unfortunately, as with any such generic term, the truth is missed. The ventilator is not the cause, nor the mechanism, by which the pneumonia develops. Rather, VAP usually results from introduction of bacteria into the trachea due to the presence an artificial airway introduced into the trachea. The term artificial airway acquired pneumonia has been suggested and is a more accurate description. ${ }^{1,2}$ Recent studies have evaluated design changes to the endotracheal tube in relation to VAP. The evidence about these design changes has been either inconclusive, that the design change was ineffective, or the design change was cost-prohibitive. ${ }^{2}$

VAP is one of the most common of nosocomial infections and costs millions of dollars annually. It is also associated with the human cost of prolonged hospital stay, longer time on the ventilator, and, in some cases, death. The morbidity and mortality related to VAP ranges widely, depending on the diagnosis and severity of illness. ${ }^{3}$ In an attempt to decrease the incidence of VAP, the Institute for Healthcare Improvement introduced the VAP bundle to influence VAP rates in intensive care units. ${ }^{4}$

Several practices are recommended to prevent or attenuate the risk of developing VAP. These include maintaining the patient's head $\geq 30^{\circ}$, oral antisepsis, and proper inflation of the endotracheal tube cuff. ${ }^{4}$ Each of these tasks is dependent upon clinician effort, and adherence is poor without frequent reminders. ${ }^{5}$ Ideally, it would be preferable to introduce a VAP prevention practice that is independent of the clinician and does not require frequent reminders, but without compromising care.

Evidence supports the hypothesis that oral secretions that leak past the endotracheal tube cuff are often the source of VAP. Because there is wide variability in the shape of the human trachea, ${ }^{6}$ longitudinal folds (microchannels) typically form along the inflated cuff. Secretions can flow through these microchannels and colonize the lower airway., ${ }^{2,-11}$ The flow of secretions past the cuff is determined by the height of the column above the cuff, the angle of inclination, the cuff inflation pressure, and the tracheal pressure applied by the ventilator.9,12-14 The ad- dition of PEEP has been shown, both in vivo and in vitro, to counterbalance this hydraulic force and to limit the leakage past the cuff. $9,13,14$

The endotracheal tube and cuff were recently examined for their contributions to VAP. Several studies looked at cuff design and how it affects microaspiration under various conditions. ${ }^{2,8-11}$ Other studies have evaluated antimicrobial properties of new materials incorporated into the endotracheal tube design. ${ }^{7}$ Although a silver-impregnated endotracheal tube may reduce the risk for VAP, ${ }^{7}$ the costeffectiveness of this device is yet to be determined.

\section{See the Original Study on Page 1095}

In this issue of Respiratory CARE, Kolobow et al ${ }^{15}$ describe a novel cylindrical endotracheal tube cuff made of Lycra polyurethane. The purpose of the study was to create a cuff that would not have longitudinal folds and would thus prevent subglottic secretions from colonizing the lower airway. This bench study compared the new Lycra cuff to 2 other commercially available cuffs: a standard polyvinyl chloride, and a newer polyurethane cuff. All the tubes tested were inserted into a model trachea consisting of a smooth-walled acrylic tube $20 \mathrm{~mm}$ in diameter (the mean diameter of the human trachea ${ }^{6}$ ). After cuff inflation, $15 \mathrm{~mL}$ of colored water was added on top of the cuff, and they measured the time required for the water to leak past the inflated cuff.

Kolobow's finding of relatively poor performance of the polyvinyl chloride cuff, compared to the polyurethane cuff, is consistent with other studies. ${ }^{8-10,13}$ However, the study's measurement conditions did not include PEEP or mechanical ventilation, so the benefit of the new cuff in the presence of positive-pressure ventilation is unknown, given that PEEP influences the rate of fluid leak.9,12-14,16

The selection of a round, inflexible acrylic tube for a trachea model, although common in the literature, ${ }^{3,8,11}$ may not translate in vivo, because the most common tracheal cross-sectional shape is an ellipse. ${ }^{6}$ Young et al reported that, with an acrylic tube as the trachea model, all the endotracheal tube cuffs tested demonstrated leak, but only $45 \%$ of the tubes had a leak when examined in a porcine trachea. ${ }^{11}$ The human trachea, unlike a rigid trachea model, is flexible, and its dimensions change with the application 
of positive pressure. The use of colored water as a surrogate for oral secretions is suitable, because, although secretions are more viscous than water, water represents a worst-case scenario.

Because of the cylindrical shape of the experimental Lycra cuff, perhaps its morphological properties affected the rate of leakage. Also, the cuff inflation pressure used was greater than what is considered safe. ${ }^{17}$ Although Kolobow et al suggest that the majority of this pressure is attenuated by the high elasticity of the Lycra, evidence to support that is not presented in the paper.

I am curious as to the reason the Lycra cuff was formed onto a borosilicate glass mandrel rather than directly onto the endotracheal tube. It would appear that fashioning the Lycra cuff directly onto the ETT could lessen the possibility for tearing the thin membrane. That said, Kolobow's novel method of cuff assembly could lead to innovative tube design and perhaps local customization and manufacturing with computer aided design and manufacturing techniques.

Kolobow et al have added to the evidence that the artificial airway and, most importantly, the cuff may be essential when considering VAP prevention strategies. However, additional clinical evidence is needed before widespread adoption of any of the newer cuff designs can be recommended. Not only does it need to be shown that these designs reduce microaspiration, but, more importantly, it will need to be shown that they contribute to a cost-effect reduction in VAP. Until then, efforts should be placed on improving clinician adherence to low-cost VAP prevention efforts that have already been shown to be effective.

\section{Daniel F Fisher MSc RRT \\ Respiratory Care Services Massachusetts General Hospital Boston, Massachusetts}

The author has disclosed no conflicts of interest.

Correspondence: Daniel F Fisher MSc RRT, Respiratory Care, Massachusetts General Hospital, 55 Fruit Street, Blake 652, Boston MA 02114. E-mail: dfisher2@partners.org.

DOI: $10.4187 /$ respcare. 01460

\section{REFERENCES}

1. Hess DR. Noninvasive positive pressure ventilation and ventilatorassociated pneumonia. Respir Care 2005;50(7):924-931.

2. Deem S, Treggiari MM. New endotracheal tubes designed to prevent ventilator-associated pneumonia: do they make a difference? Respir Care 2010;55(8):1046-1055.

3. Dave MH, Frotzler A, Spielmann N, Madjdpour C, Weiss M. Effect of tracheal tube cuff shape on fluid leakage across the cuff: an in vitro study. Br J Anaesth 2010;105(4):538-543.

4. Institute for Healthcare Improvement. IHI improvement map: ventilator bundle 2009. http://www.ihi.org/imap/tool/ \#process $=0 \mathrm{f} 029 \mathrm{~d} 21-\mathrm{a} 307-4663-9 \mathrm{~d} 64-07 \mathrm{da} 43 \mathrm{f} 3 \mathrm{f} 857$. Accessed June 13, 2011.

5. Kollef M. SMART approaches for reducing nosocomial infections in the ICU. Chest 2008;134(2):447-456.

6. Mehta S, Myat HM. The cross-sectional shape and circumference of the human trachea. Ann R Coll Surg Engl 1984;66(5):356-358.

7. Kollef MH, Afessa B, Anzueto A, Veremakis C, Kerr KM, Margolis $\mathrm{BD}$, et al. Silver-coated endotracheal tubes and incidence of ventilator-associated pneumonia: the NASCENT Randomized Trial. JAMA 2008;300(7):805-813.

8. Lorente L, Lecuona M, Jimenez A, Mora ML, Sierra A. Influence of an endotracheal tube with polyurethane cuff and subglottic secretion drainage on pneumonia. Am J Respir Crit Care Med 2007;176(11): 1079-1083.

9. Pitts R, Fisher D, Sulemanji D, Kratohvil J, Jiang Y, Kacmarek R. Variables affecting leakage past endotracheal tube cuffs: a bench study. Intensive Care Med 2010;36(12):2066-2073.

10. Young PJ, Rollinson M, Downward G, Henderson S. Leakage of fluid past the tracheal tube cuff in a benchtop model. Brit J Anaesth 1997;78(5):557-562.

11. Young PJ, Pakeerathan S, Blunt MC, Subramanya S. A low-volume, low-pressure tracheal tube cuff reduces pulmonary aspiration. Crit Care Med 2006;34(3):632-639.

12. Lucangelo U, Zin WA, Antonaglia V, Petrucci L, Viviani M, Buscema $\mathrm{G}$, et al. Effect of positive expiratory pressure and type of tracheal cuff on the incidence of aspiration in mechanically ventilated patients in an intensive care unit. Crit Care Med 2008;36(2):409-413.

13. Zanella A, Scaravilli V, Isgrò S, Milan M, Cressoni M, Patroniti N, et al. Fluid leakage across tracheal tube cuff, effect of different cuff material, shape, and positive expiratory pressure: a bench-top study. Intensive Care Med 2010;37(2):343-347.

14. Manzano F, Fernández-Mondéjar E, Colmenero M, Poyatos ME, Rivera R, Machado J, et al. Positive-end expiratory pressure reduces incidence of ventilator-associated pneumonia in nonhypoxemic patients. Crit Care Med 2008;36(8):2225-2231.

15. Kolobow T, Cressoni M, Epp M, Corti I, Cadringher P, Zanella A. Comparison of a novel lycra endotracheal tube cuff to standard polyvinyl chloride cuff and polyurethane cuff for fluid leak prevention. Respir Care 2011;56(8):1095-1099.

16. Ouanes I, Lyazidi A, Danin PE, Rana N, Bari A, Abroug F, et al. Mechanical influences on fluid leakage past the tracheal tube cuff in a benchtop model. Intensive Care Med 2011;37(4):695-700.

17. Mehta S. Safe lateral wall cuff pressure to prevent aspiration. Ann R Coll Surg Engl 1984;66(6):426-427. 